\title{
Response to "Endovascular Management of a Rare Cause of Bleeding Per Vaginam: A Hole in the Mole"
}

\author{
Vivek Agarwal ${ }^{1, *} \quad$ Ujjwal Gorsi ${ }^{1, *}$ \\ ${ }^{1}$ Department of Radiodiagnosis and Imaging, Postgraduate Institute \\ of Medical Education \& Research, Chandigarh, India
}

J Clin Interv Radiol ISVIR 2020;4:64-64

We read with great interest an article by Chahal et $\mathrm{al}^{1}$ published in your esteemed journal in August 2019. First of all, we would like to congratulate all the concerned authors on their technical and clinical success in endovascular glue embolization in a uterine artery pseudoaneurysm associated with gestational trophoblastic disease. As discussed by the authors, endovascular embolization is very effective in the management of these cases, with the advantages of being a minimally invasive, lifesaving, and uterus-saving procedure.

Though endovascular access is also the preferred approach at our institute in managing uterine pseudoaneurysms, we have recently published an article on our experience of using percutaneous n-butyl cyanoacrylate (BCA) to manage these pseudoaneurysms, with high technical success and good clinical outcome. ${ }^{2}$

We used ultrasonography (USG) and fluoroscopy guidance to access and percutaneously inject glue (n-BCA) in pseudoaneurysms at varied sites, which included three cases of uterine artery pseudoaneurysms. The percutaneous approach is easier and has several advantages such as reduced radiation dose, reduced contrast requirement, shortened procedure time, and economically affordable treatment especially for patients in developing countries like India. Percutaneous glue injection can be useful in patients with deranged coagulation

*These authors contributed equally to the manuscript.
Address for correspondence Ujjwal Gorsi MD, Department of Radiodiagnosis and Imaging, Postgraduate Institute of Medical Education \& Research, Sector-12, Chandigarh, India (e-mail: ujjwalgorsi@gmail.com).

profile in whom endovascular or surgical treatment may result in hemorrhagic complications. We chose those pseudoaneurysms for percutaneous glue injections which were clearly visible on USG and Doppler, had favorable dome-neck ratios, surrounding hematoma that prevents spill of glue in abdominal cavity, and lacked direct arteriovenous communication. We routinely perform preprocedural CT angiography to rule out obvious arteriovenous communication.

We would like to emphasize that although the endovascular approach is the mainstay for managing uterine pseudoaneurysms, USG and fluoroscopic-guided percutaneous glue approach can be used as primary treatment options in an emergent situation in certain patients with good outcomes.

\section{Conflict of Interest}

None.

\section{References}

1 Chahal A, Malla S, Gamanagatti S. Endovascular management of a rare cause of bleeding per vaginam: a hole in the mole. J Clin Interv Radiol ISVIR 2019;3:122-125

2 Gorsi U, Chaluvashetty S, Kalra N, et al. Percutaneous glue embolization as a primary treatment for visceral pseudoaneurysms. Minim Invasive Ther Allied Technol 2019;23:1-7
DOI https://doi.org/

$10.1055 / \mathrm{s}-0040-1705266$

ISSN 2457-0214.
License terms

() (1) $\ominus \circledast$ 